occur with the development of subphrenic air. Bleeding is usually small and intermittent. Severe bleeding may occur often in cases with only a few diverticula. Coincident carcinoma occurs in $4-8 \%$ of patients with diverticular disease. It is usually extremely difficult to diagnose. When the sigmoid is narrowed by diverticular disease the stricture is usually longer than in a carcinoma; there may be funnelling at both ends while some degree of distensibility and mucosal folds may be present. The classical overhanging edges of a carcinoma are not found. Arteriography is, as yet, of no value in this difficult differential diagnosis. The position may alter in the future with the development of microangiography..$^{76}$

\section{Differential Diagnosis}

A wide spectrum of disease, both functional and organic, has to be borne in mind in considering the differential diagnosis.

\section{Irritable Colon}

There are certain well-marked radiological features in these cases :

(a) Overdistension and ballooning of the rectum may occur initially due to sigmoid spasm. If the barium flow is slowed or stopped this usually disappears.

(b) The sigmoid or often the whole left colon may be narrowed and underfilled.

(c) The patient often experiences- cramp-like pain in the left lower abdomen and desire to empty the bowel. The attacks of pain are seen to correspond with the colonic contraction.

(d) These contractions may empty the bowel downwards from the splenic flexure causing further distension of the rectum.

(e) Complete filling of the colon may not be obtained-this often means that a film of the fully distended caecum is not obtained.

(f) The post evacuation film may show a narrowed descending colon with linear folds which are regular and not oedematous as in ulcerative colitis.

\section{Carcinoma}

This has been discussed previously.

\section{Crohn's Disease}

This has been discussed in detail by G. T. Schmidt, ${ }^{72}$ who divided these cases into two types-namely, diverticulitis complicated by Crohn's disease, and Crohn's disease presenting as diverticulitis.

The extent and severity of the diverticular changes may be considerable, while the combined disease is more common in women. On barium enema four features are suggestive of this complication. Firstly, fistulæ are common; secondly, spiking, which is blind and haphazardly distributed, may be present; thirdly, the lesion may be extensive; and, fourthly, mucosal ulceration distal from the diverticula may be found. We have found that in some of these cases in which a previous barium enema has shown numerous diverticula there may be a progressive decrease in the number of diverticula and an increase in the bowel narrowing due to fibrosis.

\section{Ischaemic Colon}

In these cases the stricture is usually smooth and tapering with a concentric lumen. The folds are thick and rigid. One border may be flat while large asymmetric pseudodiverticula may develop on the opposite side. These changes may develop and progress rapidly over a period of four to six weeks.

\section{Scleroderma}

In scleroderma the diverticula are large and squaremouthed. The normal haustral pattern is disturbed and the diverticula are usually on the antimesenteric border.

\section{Infections}

Tuberculosis, bacillary dysentery, and schistosomiasis may rarely simulate diverticular disease.

\section{Endometriosis}

Classically this may show a unilateral shelf-like filling defect in the sigmoid. (Fig. 5)

\section{After Radiation}

After therapeutic pelvic radiation, usually in women, narrowing of the sigmoid may occur. This is often associated with changes in the lower small bowel. In both areas there is extensive loss of normal mucosal pattern.

To sum up, the spectrum of radiological changes in diverticular disease of the colon is wide, and radiology must be combined with clinical and pathological investigations to reach a correct diagnosis.

\title{
Surgical Management
}

\author{
M. C. T. REILLY,* M.S., F.R.C.S.
}

Until recently the surgical treatment of diverticulitis was confined to treating the complications of the disease, and, except in advanced cases, no attempt was made to treat the primary condition. Nevertheless, because of increasing knowledge about the primary muscular abnormality which seems to underlie the condition ${ }^{26} 27$ and advances in the fields of antibiotics and electrolyte balance, planned surgical intervention can be undertaken with rather more confidence than before. ${ }^{78}$ Thus, though the surgery of complications still plays a major part in the treatment of diverticular disease, "preventive surgery" is beginning to assume greater importance. To underline the possibilities of preventive rather than radical treatment it is necessary to refer briefly to certain features of the condition.

* Consultant surgeon, Plymouth General Hospital, Plymouth, Devon.
In normal health the rectum is empty. The sigmoid colon is the reservoir for faeces, and only when the gastrocolic reflex comes into play are faeces propelled thence through an apparent physiological rectosigmoid sphincter into the rectum. Whatever the relative importance of diet, emotion, or other factors in the aetiology of the muscular abnormality in diverticular disease, ${ }^{407980}$ undoubtedly in most cases the condition begins in the lower sigmoid and spreads proximally as it becomes more serious. Whether or not a physiological rectosigmoid sphincter is demonstrable anatomically, one is certainly encountered by sigmoidoscopists at $15 \mathrm{~cm}$. from the anal margin, and by radiologists, who may find that considerable pressure is needed in the rectum before a barium enema will enter the sigmoid colon, after which it will run round the remainder with relative ease. The recognized long-term ten- 
dency towards the proximal spread of diverticular disease has led many surgeons to believe that this is a progressive condition in which most of the left-sided colon is at risk.

\section{Primary Surgical Treatment}

If medical treatment of chronic diverticular disease has failed and an organic and irreversible obstruction is present, then traditionally the affected bowel should be excised and an end-to-end anastomosis performed. ${ }^{81} 82$ Those who believe that the disease is progressive carry out a wide excision, removing colon above the obviously affected portion as a prophylactic measure. Such wide excision demands full mobilization of the left colon-and sometimes transverse colon-to get a satisfactory anastomosis to the lower sigmoid or rectosigmoid. To obtain a good anastomosis it is also necessary to mobilize the rectosigmoid, and, according to the degree of mobilization possible, the line of section may run through the rectosigmoid junction, above it, or below it.

The results of this operation have usually been excellent. Sometimes, however, symptoms may recur and diverticular disease can again be shown above the line of anastomosis. This has lent weight to the view that much of the bowel "at risk" above the obviously diseased bowel should be removed. I believe that the success of some operations and the failure of others is due not so much to going high enough but to not going low enough. If the physiological rectosigmoid sphincter is removed then the functional obstruction which may have a causal role in the development of the disease is also removed. The colon above is therefore not required to develop abnormal pressures to force motions along, and diverticular "blowouts" will not develop in areas of increased intraluminar pressure. ${ }^{83}$ 84 Furthermore, diverticula which may already exist will not be subjected to high pressures and therefore will be less likely to develop complications.

\section{Sigmoid Myotomy}

Hence the operation of colectomy for diverticular disease is a major one, even in the absence of complications which may lead to shortening and thickening of the mesentery. For these reasons I was led to attempt a new surgical approach to diverticulitis. ${ }^{8588}$ Often lengths of colon removed for uncomplicated diverticular disease showed no obvious abnormality apart from thickening of the muscle coat. The muscle thickening itself seemed to involve both the circular and longitudinal fibres. In the normal colon the two antimesenteric longitudinal taeniae are fairly widely separated. In the colon which is the seat of diverticular disease, even if the diverticula themselves are not obvious (either because they are small or because they are hidden in appendices epiploicae) the longitudinal taeniae are shortened and thickened so that there is only a small slit between them. The thickening of the circular muscle, which is even more obvious, may be due partly to the concertina effect of the shortened longitudinal fibres, but also to hyperplasia or hypertrophy or both. There is also an element of oedema.

These appearances of the cut muscle are, in fact, very similar to those of the pyloric muscle in congenital hypertrophic pyloric stenosis. It seemed possible that an operation similar to Rammstedt's might be of benefit when dealing with the thickened sigmoid colon. I have been carrying out such an operation now for some seven years with results that seem to compare favourably with those obtained by orthodox methods, and this is also the experience of other surgeons. ${ }^{87} 88$ The most suitable patients for the operation-termed "sigmoid myotomy"-are those with a long history of intermittent discomfort and disability from diverticular disease, often having been admitted to hospital from time to time for medical treatment. The severity of the condition may not have been thought sufficient to warrant major surgery; nevertheless, the patients have always been at risk of complications and sometimes in continued discomfort. Sigmoid myotomy, if carefully and correctly carried out, is a relatively minor procedure, restores a normal, comfortable bowel habit, and seems to arrest the progress of the disease. ${ }^{89-9}$

So far I have used it principally for patients over 50 years of age, and the total is now some 70 cases. In the younger patient the condition may be reversible by correct medical treatment and diet. The former should include antispasmodics, the latter should contain plenty of roughage to provide bulk in the sigmoid reservoir. Sometimes even in the older patient laparotomy will reveal a surprisingly normal looking sigmoid colon, with some diverticula, but minimal thickening of the muscle coat. In such cases as well I have usually proceeded to a myotomy. The results have been satisfactory, though possibly they would have been just as good on medical treatment without any surgical intervention.

\section{Technique}

To carry out the operation properly the colon must be adequately mobilized and the surgeon must be able to get right down over the rectosigmoid junction.

For this reason a mid-line lower abdominal incision is preferred to a paramedian. The sigmoid colon is carefully mobilized from the left iliac fossa by division in a bloodless plane of the folds of peritoneum which bind the lateral surface of the mesentery to the pelvic wall. No division or mobilization of the mesentery itself is needed. Once the colon is held ou straight and taut an incision is made directly in the mid-line antimesenterically from over the rectosigmoid junction up as far as is necessary, usually $10 \mathrm{in}$. to $15 \mathrm{in}$.

The preliminary incision is made with a scalpel, after which the incision is deepened carefully with scissors. The lips of the incision are kept apart by two pairs of Allis's forceps, which are moved down alternately along the bowel as the operation progresses. The upper end of the incision will usually be an inch or so above the area of thickening palpable in the muscle wall and will also be indicated by separation of the two antimesenteric taeniae which lie close together over the affected length of bowel. The incision lies in the slit between them but may deviate slightly on to one or other if occasion demands.

As the incision deepens the circular fibres can be easily identified and divided until the mucous membrane bulges. If in doubt it is better not to be too thorough, as some of the deeper strands may be sub-mucous blood vessels. In the mid-line, however, these are only small and though they may cause a little troublesome bleeding, it soon stops with the application of a wet swab. During this time the incision can be deepened elsewhere. Ligature or cautery should not be used as this may lead to necrosis and perforation later.

Sometimes the thickened circular muscle may be slow to retract and it may be felt that myotomy has not been adequate. In such cases again it is better to deepen the incision elsewhere and then come back, when it will be found that the thickened muscular fibres have retracted and usually the mucous membrane is bulging well. Any remaining fibres can then be more easily identified and divided if necessary.

If sufficient care is taken perforation of the mucous membrane should not occur. If it does the mucous membrane should be simply sutured with fine catgut and a drain should be inserted at the end of the operation. If there is no perforation there is no necessity to drain. The incision is no covered in any way; more especially omentum is not dragged down and sewn over it. This procedure may only lead to bands and subsequent complications from obstruction. It is sufficient merely to turn the incised surface of the bowel. to the left lateral wall of the pelvis. On only one occasion have there been postoperative complications, from adhesion of loop of small intestine to the site of myotomy. In this case the mesentery was so short that the myotomy was left facing directly forwards, and it might have been better to have arranged for some covering by omentum.

\section{Surgery of Complications}

The complications of diverticulitis are: perforation and peritonitis, whether local or general; intestinal obstruction: fistulae of various types, and haemorrhage. The patient with perforated diverticulitis may be admitted to hospital with an "acute abdomen" or may develop the latter shortly after admission for observation and treatment. In the latter case frequently the patient has been given morphine. This has 
been shown to increase the intraluminar pressure, ${ }^{30}$ and is probably an important factor in producing a perforation where otherwise it might not have occurred. Morphine is contraindicated in the treatment of diverticulitis at any stage. Pethidine, which has little or no effect on intracolonic pressure patterns, is to be preferred.

Many patients who come to emergency laparotomy for obvious peritonitis have the cause of the peritonitis diagnosed only at operation. If this is a perforated diverticulum, judgement and experience are necessary to decide the correct course of treatment. If the perforation is only small, with a localized pocket of pus, all that may be necessary is to insert a drain and, if possible, oversew the perforation. This is usually difficult, however, as the tissues are friable and all that may happen is that the perforation is made larger. If sufficient omentum is available to cover the area this may be used, but it is inadvisable to mobilize omentum from higher up-thus spreading infection - to obtain a problematical coverage of a small perforation. In most cases of peritonitis due to a small perforation, indeed, the perforation may be so small that it is never discovered, and it is sufficient merely to drain. Either the perforation will heal on its own, or occasionally a faecal fistula may form, which will discharge along the drainage track and may be dealt with later.

When there is a large perforation, or any signs of obstruction, it has usually been considered advisable to carry out a proximal defunctioning colostomy and leave the abdomen to settle down for a few weeks until definitive surgery can be undertaken. Almost invariably this procedure is all that is necessary, but occasionally on opening the abdomen again persistent pus is found to be lurking between adjacent coils of kinked colon in the pelvis. This usually is due to faeces impacted above the site of the perforation. When a larger perforation is discovered at laparotomy it is, of course, essential to carry out some procedure in addition to simple drainage. Proximal colostomy is usually sufficient, but again there may be continued peritoneal contamination by faecal leakage. Frank faecal peritonitis discovered at laparotomy usually carries a high mortality whatever is done.

Some surgeons feel that faecal peritonitis, or the risk of it developing later, demands more radical surgery than simple drainage and proximal colostomy. ${ }^{57} 58$ In recent years immediate emergency resection of the affected colon has been advocated, with the establishment of a terminal left iliac colostomy. The open lower end of the bowel is closed in the manner of a Hartmann resection. The colostomy may be permanent, or an attempt to rejoin the bowel may be made later if too much bowel has not been removed. There is much to be said for this procedure as a life-saving measure, in the hands of quick and competent surgeons with good anaesthetists, for the patients are gravely ill. It seems doubtful, however, whether this procedure should be advocated in all cases, for several of these patients are dealt with at night by junior surgeons and anaesthetists. Probably a factor which should carry most weight in deciding is whether masses of faeces are palpable above the affected area of colon or not. This may not be easy to decide, for often the whole length of bowel is grossly thickened and inflamed and palpation of the contents of its lumen is impossible. In such circumstances it must be left to the judgement of the individual surgeon what to do: "When in doubt, cut it out," or "When in doubt leave it alone and make a colostomy above." In my experience the latter course has proved satisfactory in most cases and has the added advantage of leaving bowel which may recover and perform a useful function later.

\section{Faecal Fistulae}

Faecal fistulae to the skin usually result from simple drainage or inadequate surgery. Other fistulae result from local perforation and abscess formation with adherence to adjacent organs. The most dramatic in its results is the vesicocolic, but colocolic and enterocolic fistulae may also occur. Very rarely the left ureter may be involved in a fistula. The surgical treatment of fistulae demands the invariable excision of the portion of bowel involved. Attempts simply to oversew a fistulous opening after dividing it from the organ with which it communicates usually fail, for there is too much fibrosis for healthy healing to take place. For safety's sake a proximal colostomy is usually performed before dealing with any fistula, but thereafter the extent of the excision of involved bowel is a matter of personal choice. Some surgeons prefer to do a wide resection of all bowel involved, while others may believe, with the author, that it is necessary to excise only a small portion of the bowel involved containing a fistula and to carry out an anastomosis with a myotomy above or below, or both, as may seem necessary.

\section{Haemorrhage}

Severe haemorrhage is usually more common in the early stages of the condition rather than the late-that is, in diverticulosis rather than diverticulitis. This presumably results from trauma to a perforating vessel beside the neck of the diverticulum. The haemorrhage may be profuse and alarming, but almost invariably stops spontaneously. If one carries out a laparotomy during the bleeding stage it is usually impossible to localize accurately the site of the bleeding. One is left with the choice between resecting a portion of sigmoid colon "blind" or, if there is no obvious diverticular disease in the sigmoid colon, opening successive lengths of the colon between clamps to see if one can determine from which segment the bleeding is coming. Usually one cannot. Patience and blood transfusions will be found the most rewarding course. Colostomy is of no help in such cases.

\section{REFERENCES}

1 Cruveilhier, J., Traité d'Anatomie Pathologique Générale, Vol. 1, p. 492. Paris, Baillière, 1849 .

Habershon, S. O., Pathological and Practical Observations on Diseases of the Alimentary Canal, p. 296. London, Churchill, 1857.

Cripps, W. H., The Passage of Air and Faeces from the Urethra, p. 4. London, Churchill, 1888

- Morison, R., Surgical Contributions from 1881-1916, p. 625. Bristol, Wright, 1916.

- Keith, A., British Medical fournal, 1910, 1, 376

- Telling, W. H. M., and Gruner, O. C., British fournal of Surgery, 1917, $4,468$.

Spriggs, E. I., and Marxer, O. A., British Medical fournal, 1926, 1, 130.

- Spriggs, E. I., British Medical fournal, 1929, 2, 569.

- Grout, J. L. A., British fournal of Radiology, 1949, 22, 442

Pemberton, J. D. J., Black, B. M., and Maino, C. R., Surgery, Gynecology and Obstetrics, 1947, 85, 523.

11 Ransom, H. K., Gastroenterology, 1954, 26, 12

12 Welch, C. E., Allen, A. W., and Donaldson, G. A., Annals of Surgery, 1953, 138, 332.

13 Fifield, L. R., Lancet, 1927, 1, 277.

16 Kocour, E. J., American fournal of Surgery, 1937, 37, 433.

is Dearlove, T. P., Medical fournal of Australia, 1954, 1, 470.

10 Parks, T. G., Proceedings of the Royal Society of Medicine, 1968, 61, 932

17 Hughes, L. E., Gut, 1969, 10, 336.

Manousos, O. N., Truelove, S. C., and Lumsden, K., British Medical Fournal, 1967, 3, 762.

10 Badia, P. D., American fournal of Surgery, 1945, 67, 536.

10 Bearse, C., fournal of American Medical Association, 1946, 132, 371.

11 Drummond, H., British Fournal of Surgery, 1917, 4, 407.

12 Noer, R. J., Annals of Surgery, 1955, 141, 674

13 Davies-Colley, R., British Medical fournal, 1926, 1, 282.

26 Lockhart-Mummery, J. P., Lancet, 1930, 1, 231

25 Morson, B. C., Proceedings of the Royal Society of Medicine, 1963, 56, 798

Morson, B. C., British fournal of Radiology, 1963, 36, 385

Fleischner, F. G., Ming, S.-C., and Henken, E. M., Radiology, 1964, 83, 859.

28 Arfwidsson, S., Acta Chirurgica Scandinavica, 1965, Suppl. 342.

20 Williams, I., British fournal of Radiology, 1963, 36, 393.

Painter, N. S., Annals of the Royal College of Surgeons of England, 1964, 34, 98 .

1 Painter, N. S., American Fournal of Digestive Diseases, 1967, 12, 222

32 Painter, N. S., and Truelove, S. C., British Medical fournal, 1963, 2, 33

so Wilson, R. R., British fournal of Surgery, 1950, 38, 65.

36 Barling, S., British Medical fournal, 1926, 1, 322 . 
36 Slack, W. W., Gut, 1966, 7, 668.

36 Manousos, O. N., Truelove, S. C., and Lumsden, K., British Medical

3 Cleave, T. L., Campbell, G. D., and Painter, N. S., Diabetes, Coronary

Thrombosis and the Saccharine Disease, 2nd edn. Bristol, Wright, 1969.

38 Wangel, A. G., and Deller, P. J., Gastroenterology, 1965, 48, 69.

30 Wierda, J. L., Archives of Pathology, 1943, 36, 621.

¿ Carlson, A. J., and Hoelzel, F., Gastroenterology, 1949, 12, 108.

1 Morgan, M. N., and Ellis, H., British Medical fournal, 1969, 2, 53.

1 Painter, N. S., British Medical fournal, 1968, 3, 475.

13 British Medical fournal, 1970, 2, 126.

¿t Ming, S.-C., and Fleischner, F. G., Surgery, 1965, 58, 627.

is Parks, T. G., British Medical fournal, 1969, 4, 642.

4s Parks, T. G., Connell, A. M., Gough, A. D., and Cole, J. O. Y., British Medical fournal, 1970, 2, 136.

$\triangle$ Fleischner, F. G., and Ming, S.-C., Radiology, 1965, 84, 599.

it Lyall, A., British fournal of Surgery, 1936, 24, 192.

to Cooke, W. T., Lancet, 1937, 1, 84 .

so David, V. C., and Gilchrist, R. K., Annals of Surgery, 1938, 107, 801.

"S Shaldon, C., British fournal of Surgery, 1958, 45, 357 . 1950, 91, 612.

so MacLaren, I. F., fournal of the Royal College of Surgeons of Edinburgh, $1957,3,129$.

- Dawson, J. L., Hanon, I., and Roxburgh, R. A., British fournal of Surgery, 1965, 52, 354 .

ss Hughes, E. S. R., and Shaw, H. M., Medical fournal of Australia, 1952, $1,259$.

se Staunton, M. D. M., British Medical fournal, 1962, 1, 916.

s7 Madden, J. L., American Surgeon, 1965, 31, 781.

so Large, J. M., Lancet, 1964, 1, 413.

soxburgh, R. A., Dawson, J. L., and Yeo, R., British Medical fournal, $1968,3,465$.

-o Tagart, R. E. B., British Fournal of Surgery, 1969, 56, 417

1 Ryan, P., British fournal of Surgery, 1958, 45, 611.

12 Fraenkel, G. J., British fournal of Surgery, 1954, 41, 643.

is Asch, M. J., and Markowitz, A. M., Surgery, 1967, 62, 239.
-4 Brown, H. W., and Roy, S., International Surgery, 1968, 49, 135.

os Noer, R. J., Hamilton, J. E., Williams, D. J., and Broughton, D. S. Annals of Surgery, 1962, 155, 794.

co Slack, W. W., British fournal of Surgery, 1962, 50, 185.

'7 Young, J. M., and Howarth, M. B., Annals of Surgery, 1954, 140, 128

is Quinn, W. C., Annals of Surgery, 1961, 153, 851.

Goligher, J. C., Surgery of the Anus, Rectum and Colon, 2nd edn., p. 1059 London, Baillière, Tindall and Cassell. 1967.

70 Olsen, W. R., American Fournal of Surgery, 1968, 115, 247.

11 Colcock, B. P., and Sass, R. E., Surgery, Gynecology and Obstetrics, 1954, 99, 627.

72 Schmidt, G. T., Lennard-Jones, J. E., Morson, B. C., and Young, A. C., Gut, 1968, 9, 7.

12 Manousos, O. N., Truelove, S. C., and Lumsden, K., Physiological Review, 1966, 46, 3.

76 Fleischner, F. G., in Alimentary Tract Roentgenology, ed. A. R. Margulis and H. J. Burhenne, Vol. 2, p. 784. Saint Louis, C. V. Mosby. 1967.

75 Painter, N. S., American fournal of Digestive Diseases, 1968, 13, 468.

7 Boles, R. S., jun., and Jordan, S. M., Gastroenterology, 1958, 35, 579

17 Hoar, C. S., and Bernhard, W. F., Surgery, Gynecology and Obstetrics, 1954, 99, 101

78 Smithwick, R. H., Annals of Surgery, 1942, 115, 969.

70 Wells, C., British fournal of Radiology, 1949, 22, 449.

so Lloyd-Davies, O. V., Proceedings of the Royal Society of Medicine, 1953, 46, 407

11 Muir, E. G., Lancet, 1966, 1, 195.

12 Muir, E. G., Proceedings of the Royal Society of Medicine, 1968, 61, 401.

s Painter, N. S., and Truelove, S. C., Gut, 1964, 5, 201.

s Painter, N. S., and Truelove, S. C., Gut, 1964, 5, 365.

8 Reilly, M., Proceedings of the Royal Society of Medicine, 1964, 57, 556.

is Reilly, M., British Fournal of Surgery, 1966, 53, 859

'7 Dodd, H., British Fournal of Clinical Practice, 1966, 20, 505.

\& Dick, E. T., Ncw Zealand Medical fournal, 1967, 66, 163.

so Attisha, R. P., and Smith, A. N., British fournal of Surgery, 1969, 56, 891.

so Smith, A. N., Attisha, R. P., and Balfour, T., British fournal of Surgery, $1969,56,895$.

'1 Reilly, M., Proceedings of the Royal Society of Medicine, 1969, 62, 715.
Q.-In what way does zinc sulphate lotion B.P.C. act to hasten healing in clean wounds?

A.-Zinc oxide was used in ancient Egypt as calamine to promote healing, and various zinc compounds have been used empirically for centuries as local applications.

Strain et al. ${ }^{1}$ undertook a formal study of the effect of adding zinc to strictly controlled diets of rats after preliminary studies had indicated that ingested zinc might stimulate wound healing, and because 15-20\% of stored zinc in the body is in the skin. Their findings suggested that zinc is an important factor in the repair of the skin but that an amino-acid carrier may be required for its utilization. Zinc-deficient animals may develop skin lesions which heal promptly if adequate zinc is provided.2 Strain and his colleagues showed subsequently $^{3}$ that the rate of human wound healing was accelerated by zinc. These authors also found a striking decrease in the zinc content of the hair in patients with extensive thermal burns, and suggested that zinc therapy may have a place in the treatment of burns. Zinc certainly has a positive effect upon growth and protein synthesis.

I am not aware of any controlled studies evaluating the effect of zinc sulphate lotion itself.

\section{REFERENCES}

I Strain, W. H., Dutton, A. M., Heyer, H. B., and Ramsey, G. H., Experimental Studies on the Rochester, University of Rochester Reports, 1953.

2 Zinc in Animal Nutrition. New York, American

Zinc Institute Inc., 1964.
Strain, W H., Pories, W. J., and Hinshaw, J. R.,
Surgical Forum, 1960, 11, 291.

\section{Congenital Spherocytosis}

Q.-Is there any treatment for congenital spherocytosis, and, in particular, can anything be done to stimulate growth in a child with the disease?

A.-The accepted treatment for congenital spherocytosis is splenectomy. It almost invariably produces complete symptomatic relief and will also stimulate growth in a child suffering from the disease. Interestingly enough, it does not appear to produce a significant change in the morphological and biochemical defects of the red cell.

\section{REFERENCE} Dacie, J. V., The Haemolytic Anaemias, 2nd edn.,
vol. 1. London, Churchill, 1963.

\section{Tetracosactrin and Insulin}

Q.-If rheumatoid arthritis in diabetics on insulin is treated with synthetic corticotrophin (tetracosactrin) is it more difficult to keep the patient stabilized, and should blood-sugar estimations be done more frequently than usual?

A.-I have not seen any suggestion that diabetes is more difficult to control in patients treated with tetracosactrin. When using the long-acting preparation it is worth bearing in mind that $1 \mathrm{mg}$. is approximately equivalent to 80 units of natural corticotrophin and that its effect lasts for something under 48 hours. If tetracosactrin is being substituted for A.C.T.H. it might be advisable to do more frequent blood-sugar estimations during the initial stages.

\section{Local Sensitivity to Insulin}

Q.-Some patients on insulin zinc suspension complain of an itching reaction at the site of injection soon after administration and continuing for 36 hours. This seems to be a sensitivity reaction. What can be done to prevent or treat it? Could an antihistamine be given either in the injection or separately by mouth?

A.-Local sensitivity reactions to insulin zinc suspension are usually mild and tend to disappear over the course of two to three months. An antihistamine such as promethazine may be given if necessary. If symptoms persist it may be worth changing to another brand of insulin, and in rare instances it may be necessary to desensitize the patient to insulin.

\section{Pea Blanching}

Q.-Is there any toxic hazard in attending a machine mixing sodium metabisulphite with sodium carbonate for use in a process known as pea blanching?

A.-This process for pea blanching has been used on a large scale for many years. In the preservation process the colour in the peas is reduced by the action of the bisulphite in an alkaline medium. On subsequent boiling sulphur dioxide is driven off and the colour is reformed. In normal conditions there is virtually no hazard, but if, for example, an acid were added in mistake for the alkali the irritant gas $\mathrm{SO}_{2}$ would be evolved in large amounts. There might be a slight risk of primary irritant dermatitis if sodium carbonate is handled carelessly in large quantities. 